\title{
Pre-service mathematics teachers' responding to student thinking in their teaching experiences
}

\author{
Berna Tataroğlu Taşdan ${ }^{1}$ and Makbule Gözde Didiş Kabar² \\ ${ }^{1}$ Department of Mathematics and Science Education, Dokuz Eylul University, Turkey (ORCID: 0000-0002-5851-6144) \\ ${ }^{2}$ Department of Mathematics and Science Education, Tokat Gaziosmanpasa University, Turkey (ORCID: 0000-0003-4202-2323)
}

\begin{abstract}
While noticing has received extensive attention from researchers with regards to pre-service and in-service teachers, there has been little research on how pre-service mathematics teachers respond to student thinking in the mathematical discussions. The aim of the study was to investigate pre-service mathematics teachers' (PSMTs) ways of responding to student thinking and the extent they focused on student thinking while responding to them. Two PSMTs' planned lessons were observed by the university supervisor and the cooperating teacher. Data was collected through lesson plans, video recordings of the PSMTs' teaching and the observation notes by the supervisor. The constant comparative method was performed throughout the qualitative data analysis. The results initially revealed that although PSMTs could use different types of actions such as eliciting, repeating, redirecting, teaching and encouraging to respond to student thinking during their teaching experiences, their responding to student ideas did not follow a single path or a pattern for their lessons. In terms of the ways of responding, PSMTs dominantly used eliciting, repeating, and evaluating, while explaining, extending and probing student thinking were less preferred. The results provide important cases to help mathematics teacher educators to understand the PSMTs' ways of responding to student thinking and their tendencies towards being able to focus on student thinking while responding to them. Finally, the paper discusses the educational implications of the results.
\end{abstract}

Keywords: Teacher noticing; Pre-service mathematics teachers; Responding skills; Student thinking

Article History: Submitted 1 October 2021; Revised 1 February 2022; Published online 2 March 2022

\section{Introduction}

Research in mathematics education highlights the importance of eliciting student's mathematical thinking and using it for making instructional decisions (Chamberlin, 2005; Fennema et al., 1996; Franke \& Kazemi, 2001; Lee \& Francis, 2018; National Council of Teachers of Mathematics [NCTM], 2000, 2014). Such an instruction that builds on student thinking has been linked to rich instructional environments for students and documented gains in student achievement (Jacobs et al., 2010). There have been extensive studies examining how teachers notice student thinking (e.g., Jacobs et al., 2010; Mason, 2002; Sherin \& van Es, 2005; van Es \& Sherin, 2002). Jacobs et al. (2010) conceptualized professional noticing of students' mathematical thinking as a set of three

Address of Corresponding Author

Berna Tataroğlu Taşdan, PhD, Dokuz Eylul University, Buca Faculty of Education, Department of Mathematics and Science Education, 35380, Izmir, Turkey.

$\triangle$ berna.tataroglu@deu.edu.tr

How to cite: Tataroğlu Taşdan, B. \& Didiş Kabar, M. G. (2022). Pre-service mathematics teachers' responding to student thinking in their teaching experiences. Journal of Pedagogical Research, 6(1), 87-109. https://dx.doi.org/10.33902/JPR.2022175553 
interconnected skills including (a) attending to children's strategies, (b) interpreting children's understandings, and (c) deciding how to respond based on children's understandings. These skills (attending, interpreting, responding) serve as an integrated set in teachers' deciding which mathematical ideas are worth pursuing in the moment, which follow-up questions to ask, or what tasks to put forward next (Jacobs et al., 2010; Monson et al., 2020).

Since the teacher response results in a visible action linked to internal processes of attending and interpreting students' mathematical thinking, responding is defined as the most difficult noticing skill to develop (Barnhart \& van Es, 2015; Land et al., 2019; Sánchez-Matamoros et al., 2019). In recent years, researchers have been particularly interested in how teachers respond to students' thinking during mathematical discussions (e.g., Brodie, 2008; Bywater et al., 2019; Ellis et al., 2019; Lim et al., 2020; Tyminski et al., 2020). Although there is no single best way to respond to student thinking, the teacher's response should be intended to help students deepen their conceptual understanding while moving them forward, toward procedural fluency and advanced mathematical reasoning (NCTM, 2014). Teacher's ways of responding to student thinking while orchestrating the classroom discourse, involve both questioning strategies like pressing students to provide their reasoning, asking students for alternative solutions, asking a student to predict outcomes, or probing a student thinking and other actions like revoicing, redirecting or waiting for students' answers (Bywater et al., 2019; Conner et al., 2014; Dong et al., 2019; Gaspard \& Gainsburg, 2019; Lim et al., 2020).

Studies also indicated that pre-service teachers have struggled to respond to student thinking (Krupa et al., 2017; Monson et al., 2020; Son 2016). For example, Krupa et al. (2017) investigated the impact of a structured curricular module on pre-service teachers' noticing skills. They found that although their ability to attend to and interpret student thinking was advanced, there was no change in their responding to students. Also, pre-service teachers in their study tended to focus on student errors and to describe their instructional responses in terms of fixing student mistakes. However, responding to student thinking requires eliciting and elaborating of correct thoughts of students as well as their incorrect answers. In the study of Hallman-Thrasher (2017), pre-service teachers used questioning to elicit student strategies at the beginning of the study, and, as the study progressed, they also asked follow-up questions to help students clarify their thinking. Early in the study when students presented unanticipated incorrect solutions, they asked leading questions ("What does sum that mean? It means we're adding, right?"), stated a correct approach or idea for the student to adopt ("So why don't we start with writing down numbers that add up to 6?"). With the field experience embedded in a practiced-based mathematics methods course, they learned to ask students to test their conjectures and draw conclusions based on the work (Hallman-Thrasher, 2017).

Although the results of the studies show that responding to student thinking is a difficult task for pre-service teachers, it is known that responding skill, like other noticing components, can be learned and improved through experience and time by professional development support (Jacobs et al., 2010). Thus, pre-service teachers need to be engaged in practice-based opportunities and professional development experiences during their mathematics teacher preparation programs early as possible to rehearse and develop responding skill (Hallman-Thrasher, 2017; Krupa et al., 2017; Tyminski et al., 2020). Although there has been an increasing interest of researchers, as discussed above, to the pre-service teachers' ways of responding to student thinking, more research is still needed about how pre-service mathematics teachers respond to student thinking in the mathematical discussions and how their responding skills could be enhanced. Based on this idea, we aimed to investigate pre-service mathematics teachers' (PSMTs') ways of responding to student thinking and the extent they focused on student thinking while responding to them. Our research questions were as follows:

- What were the PSMTs' ways of responding to student thinking in their lessons?

- To what extent did the PSMTs focus on student tkinking while responding to students during their lessons? 
The findings of this study will display two PSMTs' ways of responding to student thinking and their tendency whether or not they focus on student thinking while responding to students. To support their development to effectively respond to student thinking, revealing PSMTs' ways of responding is a necessary step. Therefore, this study can be considered as the first step of research investigating PSMTs' responding skills. In this way, by investigating PSMTs' responding skill as one of the fundamental components of noticing skill, this study will contribute to the growing body of research regarding teacher's noticing.

\subsection{Teacher Noticing}

Mason (2002) stated that "noticing is something that we do all the time, but as a profession, we are sensitised to notice certain things in professional situations" (p. xi). Teaching involves observing the classroom in which multiple things happen simultaneously and choosing and making sense of those aspects that are pedagogically relevant and make instructional decisions (Sherin et al., 2011).

Researchers have been interested in understanding teacher's noticing in different ways. Some have only examined what teachers attend to (Males, 2017; Star et al., 2011; Star \& Strickland, 2008), while others have also incorporated how teachers make sense and reason about the noticeable events (Santagata et al., 2007; Sherin \& Han, 2004; Sherin \& van Es, 2009; van Es \& Sherin, 2008). Jacobs et al. (2010) developed a more comprehensive perspective to mathematics teacher noticing as they considered not only teachers' attention to and interpretation of classroom activity but also teachers' decisions about how to respond. They defined a specialized type of noticing, professional noticing of children's mathematical thinking, that includes attending, interpreting, and deciding how to respond to student thinking (Jacobs et al., 2010).

Jacobs et al. (2010) emphasized that teachers must execute three noticing skills in an integrated way, almost simultaneously. Philipp et al. (2017) explained this situation with an example as follows: When a student gives an unexpected answer to a teacher's question, the teacher might ask that student or other students a follow-up question and modify the lesson based on this new situation. In this example, attending to and interpreting the first student thinking were almost inseparable, and the teacher began to formulate a response while interpreting the student thinking (Philipp et al., 2017). Therefore, three noticing skills are at play when teachers make decisions about what mathematical ideas are worth pursuing in the moment, what follow-up questions to ask, or what tasks to pose next (Monson et al., 2020). Nevertheless, deciding how to respond is both temporally and conceptually linked to attending to student thinking and interpreting them during teachers' in-the-moment decision making (Jacobs et al., 2011). Because of this link, responding is considered the most demanding noticing component by many researchers (e.g., Barnhart \& van Es, 2015; Krupa et al., 2017; Monson et al., 2020; Land et al., 2019; SánchezMatamoros et al., 2019). In recent years, researchers have addressed what responding to student thinking includes (Jacobs \& Ambrose, 2008; Jacobs \& Empson, 2016), and how this skill can be developed for pre-service teachers and teachers (Monson et al., 2020). In this study, we focused on the "responding" component of noticing, PSMTs' responding to student thinking.

\subsection{Responding to Student Thinking}

Responding have been conceived as an important teaching practice to facilitate productive mathematical discussions by the researchers (e.g., Brodie, 2008; Bywater et al., 2019; Ellis et al., 2019; Lim et al., 2020; Tyminski et al., 2020). The teacher and students participate in mathematical discussions through questions and comments, and it continues until the class comes to a consensus (Sherin, 2002). In such a discussion, the teacher asks students some questions or use some prompts and the students say their ideas. Then, the teacher may respond to student thinking in different ways depending on what she/he hears in student thinking to engage them in the discussion. Responding involves deciding what to say or do next based on student thinking and encouraging students to express more of their ideas so that they can reach the desired learning goal and future responding can occur (Bywater et al., 2019). Therefore, it is important for teachers to be prepared 
to respond to student thinking, whether correct or incorrect, and give careful and insightful feedback to students in support of effective learning (Abdulhamid \& Venkat, 2018).

The most prevalent model of classroom interactions, which teachers apply in mathematics classroom discussions, is Initiation-Response-Evaluation (IRE) pattern (Mehan, 1979). In IRE pattern, the teacher initiates the question, a student gives a response, and the teacher evaluates the response (Herbel-Eisenmann \& Breyfogle 2005). In such a discussion environment, the teacher responses to students' ideas either confirming, correcting, or leading students to reach the correct answer. Teachers' tendency to respond to the correctness of a student contribution rather than the mathematical thinking behind the contribution often leads to evaluative responses that limit potential learning opportunities (Monson et al., 2020).

With the indication of the reforms in mathematics education (e.g., NCTM, 2014; 2018), mathematical discussions began to transform more student-centered. Accordingly, many studies have discussed which of the ways the teacher respond to student thinking could be better (e.g., Jacobs \& Empson, 2016; Lim et al., 2020; Monson et al., 2020). Not all responses are equally productive for promoting student learning or building on student ideas (Munson, 2019). Monson et al. (2020) defined characteristics of good response as it (1) works toward student learning objective, (2) draws on and is consistent with the student thinking presented, (3) draws on and is consistent with research on students' mathematical development, and (4) proposed interaction with student leaves space for student's future thinking (not just teacher's thinking).

It is seen that a good response requires the teacher to focus on student thinking. Therefore, asking initial questions to elicit students' mathematical thinking could not be enough to make student thinking clear. Open-ended questions, such as "Can you say more about that?", "Why?", "What if...?", are required for students to elaborate in ways that deepen the class discussion and enhance opportunities for conceptual understanding (Gaspard \& Gainsburg, 2019). Franke et al. (2009) highlighted the potential benefits of asking multiple questions, instead of asking a single question, for teachers as they understand student thinking more fully and, therefore, to make more informed instructional decisions, such as what additional problems to pose and what questions to ask of other students to reveal the nature of their understanding. For the teacher to listen, understand and deepen the student thinking, she/he may choose ways of responding that focus on the student thinking, as defined by Wood (1998), as encouraging students to do most of the mathematical work by focusing attention on particular aspects of students' explanations without guiding students in a specific, predetermined direction. When the teachers focus on student thinking, they know what their responses tell them about students' understanding, decide how to use this knowledge in planning instruction and interacting with students, and teachers' own learning can become generative because they know how to learn more about students' thinking (Franke et al., 2001).

\section{Method}

In this study, to make a depth investigation about two PSMTs' ways of responding to student thinking during their teaching in the field experiences and the extent to what PSMTs focused on student thinking while responding to students, a qualitative case study was conducted (Yin, 2003).

\subsection{The Research Context}

This study was conducted during the spring semester of the 2017-2018 academic year in conjunction with the field experience associated with the Teaching Practicum course offered for elementary mathematics education at a public university located at a small city in Turkey. One of the authors of this study was the instructor of the Teaching Practicum course and the university supervisor of the participating PSMTs.

The duration of the Elementary Mathematics Education program is four years (eight semesters). One academic year consists of two 14-weeks excluding the final examination periods. The Teaching Practicum course is given in the $8^{\text {th }}$ (last) semester of the program. The course consists of 
the theoretical part of the field experience. The duration of the theoretical part is one 2-hour lessons a week. The Teaching Practicum course aims to provide the PSMTs with theoretical knowledge for their adaptation to classroom conditions, planning and preparation for teaching. Furthermore, the field experience is the practical part of the Teaching Practicum course and the PSMTs devote 6-hour lessons per week to the practicum in the mathematics classrooms of an elementary school. Field experience includes classroom observations, planning and teaching mathematics lessons several times. PSMTs are expected to apply their expertise in instructional strategies, classroom management and assessment to their mathematics teaching.

For this study, PSMTs planned and implemented lessons three times under the observation of the university supervisor and their cooperating teacher. PSMTs taught their lessons at 4-week intervals over the semester. The topics of the PSMTs' lessons were determined by their cooperating teacher and were presented in Table 1.

Table 1

The topics taught by each PSMT according to their lessons

\begin{tabular}{llll}
\hline PSMTs & Lesson\#1 & Lesson\#2 & Lesson\#3 \\
\hline Okan & $\begin{array}{l}\text { Calculating the length of a } \\
\text { circle and the arc length of } \\
\text { a circle }\end{array}$ & $\begin{array}{l}\text { Describing quadrilaterals and } \\
\text { the relationship between them }\end{array}$ & $\begin{array}{l}\text { Calculating the area of the } \\
\text { polygons formed by regular } \\
\text { polygons }\end{array}$ \\
$\begin{array}{l}\text { Ferman } \\
\text { circle and arc length of a } \\
\text { circle }\end{array}$ & $\begin{array}{l}\text { Describing quadrilaterals and } \\
\text { the relationship between them }\end{array}$ & $\begin{array}{l}\text { Translating a point, a line } \\
\text { segment and different shapes }\end{array}$ \\
\end{tabular}

Before teaching, PSMTs prepared a lesson plan for each lesson. The PSMTs were placed with the same cooperating teacher in the same middle school. They taught the same day in different classes of the same cooperating teachers at $7^{\text {th }}$ grade (e.g., Class 7A, Class 7C). The duration of the lesson hours was 40 minutes. Each PSMT spent approximately 5 minutes for preparing students for the lesson and 35 minutes for teaching.

The university supervisor observed and videotaped all of PSMTs' lessons. She also took relevant field notes and collected all the worksheets used by PSMTs during their teaching. At the end of each lesson, the cooperating teacher, university supervisor and PSMTs met together to evaluate PSMTs' lessons and teaching experience, however, no feedback in terms of responding was given to them since the research aimed to describe the current responding skills of the PSMTs.

\subsection{Participants}

Two PSMTs, who were in their fourth year (final year), enrolled in the Teaching Practicum course were the participants of this study. Both were male and they were selected among four PSMTs who taught under the direction of the university supervisor. Because only two of these PSMTs were volunteered to participate in this study and allowed to video record of each of their instruction, we focused on only two PSMTs among four. The PSMTs and all students in their classes were informed about the purpose of the study and data collection process. Since the study focused only on PSMTs, they were also informed about their rights and responsibilities. Furthermore, PSMTs' written consent was received before they entered the research. They were given pseudonyms as Okan and Ferman.

The grade point averages (GPAs) of PSMTs for all courses taken in their previous study were 76.22 and 48.99 on a 100-point, respectively. By the time the data were collected, the participants completed most of the courses in mathematics education focusing on teaching and learning mathematics required in the programme. As a part of some of these courses (e.g., methods course) participating PSMTs had learnt about how to question and elicit student's mathematical thinking. However, they did not get any theoretical and practical knowledge about how to respond to student's mathematical thinking. 


\subsection{Data Collection Tools and Data Analysis}

The data was collected through lesson plans, video recorded lessons of the PSMTs and observation notes. The transcripts of video recordings were used as the primary data sources. PSMTs' lesson plans and the instructor's observation notes were used as secondary data sources. Because each PSMT taught 3 times over the study, there were 6 videotaped lessons and 6 lesson plans in total.

Data analysis was performed in three phases. The first phase was to divide the PSMTs' lessons into episodes. To identify the meaningful sections of the lessons in terms of responding, it was necessary to determine what the episode would start and end with. Therefore, a sample was initially selected from the data. Transcriptions of sample data were independently examined by the researchers, and the possible episodes were identified. Natural breaks in the discourse helped to identify the episodes. Then, the determined episodes were compared and discussed until reaching a consensus about the disagreements. After a common decision for the episode was reached, the episodes in all lessons were determined separately by two researchers. As shown in Figure 1, each episode starts with PSMT's or a student's talk.

Figure 1

An example of how an episode was identified

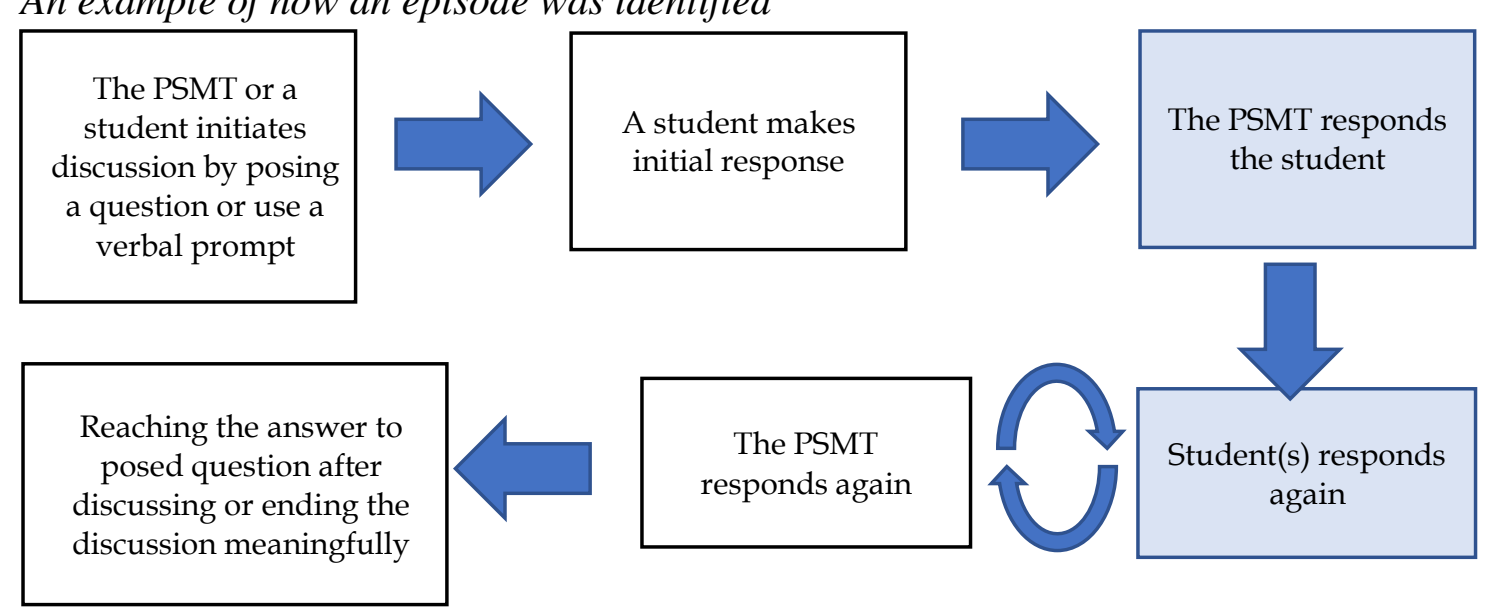

In the episodes, all initiation actions were a question or a prompt that was posed to start a discussion. The responding actions of PSMTs included either questions or verbal statements of responding to a student's statement. The episode ended when the answer to the initial question was reached and when the initiated discussion was completed. As shown in Table 2, the number of episodes differed between 5 and 23 for each lesson. The total number of responding episodes in Okan's lessons was 30, and only one of them was student initiated. In his lessons, the number of episodes was close to each other and ranged from 8 to 11. The total number of responding episodes of Ferman's lessons were 38 and 3 of them were initiated by the students. The number of episodes of Ferman's lessons varied over a wider range, from 5 to 23.

Table 2

Numbers of responding episodes

\begin{tabular}{llcc}
\hline & & \multicolumn{2}{c}{ Number of Episodes } \\
\hline PSMTs & & PSMT initiated & Student initiated \\
\hline Okan & Lesson\#1 & 11 & - \\
& Lesson\#2 & 8 & - \\
& Lesson\#3 & 10 & - \\
& Lesson\#1 & 10 & 3 \\
& Lesson\#2 & 20 & - \\
& Lesson\#3 & 5 & - \\
\hline
\end{tabular}


After the episodes were determined, the coding process was started to identify PSMTs' ways of responding to student thinking and the responding actions in the episodes. In analyzing data, the constant comparative method was utilized (Strauss \& Corbin, 1990). First, each lesson's video record including students' written work on the board was transcribed. The data from transcripts of video recordings were analyzed through open coding. Therefore, PSMTs' all responses that followup a student's response to the initiation question or prompt were focused on and coded. Furthermore, all the non-mathematical classroom talks were purposefully ignored. Each episode independently was examined and coded by the researchers, then the codes were compared and discussed. Once they reached a consensus, they developed an initial code list of the responding actions and created a codebook. Afterwards, the first author of this study recoded the data according to final codebook and the other author then reviewed the coded data through an iterative strategy. Then, the researchers met again and examined the patterns, clustered codes, and created the final categories as presented in Table 3. The name of categories was inferred from the literature (e.g., Dong et al., 2019; Ellis et al., 2019; Lim et al., 2020).

Table 3

The list of final categories and codes to examine PSMTs' ways of responding

\begin{tabular}{ll}
\hline Categories & Codes \\
\hline Eliciting (EL) & $\begin{array}{l}\text { Asking a question to remember } \\
\text { prerequisite (prior) knowledge } \\
\text { Asking a question to get a mathematical } \\
\text { answer (e.g., factual question) }\end{array}$ \\
& $\begin{array}{l}\text { Asking a question to remember what was } \\
\text { given in the previous mathematical task. } \\
\text { Asking a question to require explanation } \\
\text { student's thinking } \\
\text { Invite students to share their thoughts }\end{array}$
\end{tabular}
Examples

"For example, what did you know about $\pi ? "$

"Did you find?", "What did you find?", "What was the measure of the angle?"

What was done before?

What did you pay attention to while creating the shape? Tell me.

Please you tell.

Ok come and start telling on the board

Probing (PRB) Asking a question to require making interpretation

What do you think the reasons that why I show it in this way?

Asking a question to require clarification How did you decide that it was 6? the student's thinking (clarification) Asking a question to require justification

PSMT: Why did you say 14 ? the student's thinking (justification)

Redirecting (RD) Asking a question to direct student's attention to specific ideas/or solution strategies

"For example, have you ever tried counting the holes of our strip?"

"Well, did you notice that these are equal?"

Using some prompts to direct student's Let's first create our rhombus. Then, attention to specific ideas/or solution strategies for example, look at their circumference

Evaluating (EVA) Asking for approval

Student: The circumference of the circle

PSMT: The circumference of the circle, right?

Confirming

Student: Direct proportion

Correcting student's mistake PSMT: That is right, direct proportion Student: Was the sum of the interior angles of a quadrilateral is 180 degrees?

PSMT: Let's say 360 degrees. 
Tablo 3 continued

\begin{tabular}{|c|c|c|}
\hline Categories & Codes & Examples \\
\hline \multirow[t]{2}{*}{$\begin{array}{l}\text { Encouraging } \\
\text { (ENC) }\end{array}$} & $\begin{array}{l}\text { Encouraging students to engaging on the } \\
\text { task }\end{array}$ & $\begin{array}{l}\text { Everyone is creating it, right? } \\
\text { That is ok. Then try. }\end{array}$ \\
\hline & Appreciating the students & “Very well”, “Thank you” \\
\hline Teaching $(\mathrm{TCH})$ & Making mathematical explanations & $\begin{array}{l}\text { For a rectangle, the opposite sides are } \\
\text { equal; however, all four sides of a } \\
\text { square are equal. }\end{array}$ \\
\hline Extending (EXT) & Extending student's thinking & $\begin{array}{l}\text { Student: } 2 \pi r \\
\text { PSMT: Well, your friend said } 2 \pi r \text {, } \\
\text { that is to say "Radius" }\end{array}$ \\
\hline Explaining (EXP) & $\begin{array}{l}\text { Explaining student's thinking or } \\
\text { solutions }\end{array}$ & $\begin{array}{l}\text { So, we can find by multiplying the } \\
\text { diagonals and dividing them by two. }\end{array}$ \\
\hline \multirow[t]{2}{*}{$\begin{array}{l}\text { Repeating / } \\
\text { Rephrasing (RP) }\end{array}$} & Restating student's idea & $\begin{array}{l}\text { PSMT: What did " } 88 \text { " mean? } \\
\text { Student: the circumference of the } \\
\text { circle } \\
\text { PSMT: the circumference of the circle }\end{array}$ \\
\hline & Repeating the (initiation) question & What is the sum of its circumference? \\
\hline
\end{tabular}

In the third phase, to reveal the extent to what PSMTs focused on student thinking while responding to students, the nature of the episodes was examined in depth. Therefore, all episodes were coded by two researchers independently in terms of focusing on student thinking (ST) and non-focusing on ST (see Table 4). All disagreements were discussed until consensus was achieved. The codes and definitions of the codes were inferred from the literature. Definitions of the codes were adopted from Herbel-Eisenmann and Breyfogle (2005).

Table 4

The list of codes and explanations to reveal the extent to what PSMTs focused on student thinking

\begin{tabular}{ll}
\hline Codes & Explanations \\
\hline $\begin{array}{l}\text { Focusing student } \\
\text { thinking (F-ST) }\end{array}$ & $\begin{array}{l}\text { Throughout the entire episode, the general approach of PSMT was to focus } \\
\text { on ST. Therefore, to respond to students, PSMT asks a series of questions or } \\
\text { uses verbal prompt that guide ST. }\end{array}$ \\
$\begin{array}{l}\text { Non-Focusing student } \\
\text { thinking (NF-ST) }\end{array}$ & $\begin{array}{l}\text { To respond to students, PSMT asks a series of questions or uses verbal } \\
\text { prompt that guide students to desired end. }\end{array}$ \\
$\begin{array}{l}\text { Turning focusing into } \\
\text { non-focusing of student } \\
\text { thinking (F-ST\&NF-ST) } \\
\begin{array}{l}\text { Turning non-focusing to } \\
\text { focusing } \\
\text { thinking (NF-ST\&F-ST) }\end{array}\end{array} \quad \begin{array}{l}\text { Throughout the entire episode, while responding to students, PSMT's } \\
\text { focusing ST approach changes to focusing ST approach }\end{array}$ \\
\hline
\end{tabular}

\section{Findings}

In this section, the findings were presented separately for each PSMT to show their ways of responding to ST in each of the three lessons, and to what extent they focused on ST while responding them. Examples of episodes were also presented to examine how PSMTs responded to ST. 


\subsection{Okan's Responding to Student Thinking}

The data analysis displayed that Okan used various actions to respond to ST during his three lessons. Table 5 displays the ranking of Okan's use of responding actions from the highest to the lowest percentage according to each lesson. As seen in Table 5, while responding to ST, Okan used nine different types of actions in his first and third lesson and he used eight different types of actions in his second lesson. In all three lessons, Okan tended to use eliciting, evaluating and repeating actions. As shown in Table 5, Okan primarily preferred eliciting to ST throughout his lessons; therefore, he used eliciting action (33\%, 35\% and $28 \%$, respectively) the most in each of his lessons. Then, he used evaluating action $(24 \%, 24 \%$, and $20 \%$, respectively) and repeating action $(15 \%, 8 \%$ and $14 \%$, respectively) the second most in each of his lessons. He used probing action $(0.8 \%)$ at least in his first two lessons; however, he increased the use of probing action $(11 \%)$ in his third lesson. Like probing, encouraging action (5\%, 9\% and $11 \%$, respectively) also reached the highest value at the last lesson. Moreover, extending and explaining were relatively less preferred actions in Okan's all lessons. While he used explaining action (1\%) at least in his third lesson, he did not use it in his second lesson. The order of teaching, extending, encouraging and redirecting actions also changed from three to eight orders during his three lessons.

Table 5

Ranking of Okan's responding actions from the highest to the lowest percentage

\begin{tabular}{clclclc}
\hline & \multicolumn{2}{c}{ Lesson\#1 } & \multicolumn{2}{c}{ Lesson\#2 } & \multicolumn{2}{c}{ Lesson\#3 } \\
\hline Order of actions & Actions & $\%$ & Actions & $\%$ & Actions & $\%$ \\
\hline 1 & Eliciting & $33 \%$ & Eliciting & $35 \%$ & Eliciting & $28 \%$ \\
3 & Evaluating & $24 \%$ & Evaluating & $24 \%$ & Evaluating & $20 \%$ \\
4 & Repeating & $15 \%$ & Encouraging & $\mathbf{9 \%}$ & Repeating & $14 \%$ \\
5 & Teaching & $8 \%$ & Redirecting & $\mathbf{9 \%}$ & Probing & $\mathbf{1 1 \%}$ \\
6 & Redirecting & $6 \%$ & Repeating & $\mathbf{8} \%$ & Encouraging & $\mathbf{1 1} \%$ \\
7 & Extending & $6 \%$ & Teaching & $\mathbf{8} \%$ & Redirecting & $9 \%$ \\
8 & Encouraging & $5 \%$ & Extending & $7 \%$ & Teaching & $\mathbf{4 \%}$ \\
9 & Explaining & $4 \%$ & Probing & $0.8 \%$ & Extending & $\mathbf{4} \%$ \\
\hline
\end{tabular}

Note. ${ }^{*}$ Equal percentages are shown in bold; ${ }^{* *} H o w$ the responding actions distribute in the episodes according to each lesson of Okan was presented in Table 1 (see Appendix 1).

On the other hand, the data revealed that although Okan responded to ST by using various actions in his three lessons, he usually did not focus on ST across three lessons. Table 6 shows Okan's approach to focus ST while responding to them during his lessons. The number of episodes in which Okan focus on ST was very few in his 1st and 3rd lessons. In the 2nd lesson, the number of episodes in which Okan focuses on and non-focuses were evenly distributed. As the number of episodes indicated, Okan occasionally focused on ST while responding to students across three lessons and his general tendency was not to focus on ST in his lessons. He mostly revealed ST by using eliciting action; however, he then directed students to the way in his mind. Okan usually asked series of questions or used prompts to direct students to the desired end. Furthermore, Okan's focusing ST approach turned to a non-focusing ST approach while responding to students. That means, although he listened to students' responses and guided them at the beginning of the discussion, he then changed his approach to direct students to find an answer towards the end of the discussion. In addition, in his second and third lessons, Okan's non-focusing ST approach once turned to the focusing ST approach. In these episodes, he first tried to reveal the ST and conducted the discussion in the direction he planned, then turned to focus on the ST and guided them to reach some conclusions by themselves. 
Table 6

Okan's approach to focus ST while responding to them during his lessons

\begin{tabular}{llll}
\hline & \multicolumn{3}{c}{ Number of episodes } \\
\cline { 2 - 4 } Okan's approach to focus ST & Lesson\#1 & Lesson\#2 & Lesson\#3 \\
\hline Focusing (F-ST) & 2 & 3 & 2 \\
Non-Focusing (NF-ST) & 8 & 3 & 6 \\
Turning Focusing to Non-Focusing & 1 & 1 & 1 \\
(F-ST\& NF-ST) & & & 1 \\
Turning Non-Focusing to Focusing & - & 1 & 10 \\
(NF-ST\&F-ST) & 11 & 8 & \\
\hline Total & & & \\
\hline
\end{tabular}

In his first lesson, Okan aimed to foster students' understanding to calculate the circumference of a circle and the arc length of a circle. Okan started his teaching by asking a question "You want to calculate the circumference of the wheel of your bike, how do you do it?". Then, he handed out an activity sheet to the students. The activity included questions such as calculating the circumference of a clock with a radius of $14 \mathrm{~cm}$ and calculating the length of the circle segment between the hour and minute hands at different times. Additionally, during the lesson, Okan preferred to use the interactive whiteboard to draw the circle and talked about its properties. While talking about the properties of the circle, he interacted with students and conducted class discussions. The following episode (EP2) exemplifies how Okan used responding actions in his first lesson and whether or not he focuses on ST.

$1 \mathrm{O}$ (Okan): Did you remember the formula of the circle while finding its circumference? [Initiation Question]

2 Student (S): $2 \pi r$

3 O: Well, your friend told me that $2 \pi r$, that is radius $(r)$ [Extending- Extending students' thinking]. Ok. You said pi $(\pi)$, what do you know about pi? [Eliciting- Asking a question to remember prerequisite (prior) knowledge]

$4 \mathrm{~S}$ : Its value is 3

5 O: Don't call it the "value". Call it the approximate value. [Extending- Extending students' thinking]. Because "3.14". It is going after a comma [Teaching- Making mathematical explanation or operations]. Until where?

6 S: "infinite"

7 O: Until infinite [Repeating- Restating students' idea]. Now, let's write the circumference of the circle as a formula, so let's remember. As you can see here, " $r$ " is an important variable. Now if we change " $r$ ", that is, if we make it smaller and bigger, what will change? [Eliciting- Asking a question to require explanation students' thinking]

$8 \mathrm{~S}$ : The circumference of the circle.

9 O: The circumference of the circle, right? [Evaluating- Asking for approval] We pay attention to " $r$ ". In questions, pay attention to the size of the $r$ and the smallness of $r$. (PSMT shows the board and tells the students to take note in your notebooks). [Teaching- Making mathematical explanation or operations].

In this episode, Okan initiated a class discussion to remind students the circumference of a circle. As in the whole of his first lesson, he mostly aimed eliciting ST to respond to them and preferred to use actions such as asking questions to get a mathematical answer, asking students to remember prior knowledge and share their thinking. When Okan asked students whether they remember the formula for calculating the circumference of the circle by his initiation question, a student immediately said the correct answer " $2 \pi r$ ". However, as soon as Okan got the correct answer, he did not end the class discussion. He extended the ST by saying " $r$ " was the radius, and shared it with the class ("Well, your friends told that $2 \pi r$, it is radius"). Then, he asked the class a question about what pi was ("You said pi ( $\pi$ ), what do you know about pi?"), desiring students to go beyond memorizing the formula of the circumference of a circle and remember the meaning of each symbol (constant or variable) in the formula. In line with the students' answers, Okan 
examined the effect of the variables in the circumference formula of a circle by applying further actions such as extending ST, restating student's ideas and asking for approval. Until this moment [Lines 1-8], Okan structured the discussion on the students' answers to the questions; that is, he focused on ST. But in the last part [Line 9], instead of asking students to conclude, he followed a non-focus approach and concluded the episode by making mathematical explanations (teaching) about calculating the length of a circle as he planned to reach.

The objective of Okan's second lesson was to provide students to recognize quadrilaterals (rectangle, parallelogram, trapezoid and rhombus); to determine the angle properties, and to make relationships between them. At the beginning of the lesson, Okan asked the following questions to help students focus on the mathematical content: "What shapes come to mind when you say quadrilateral? Give examples of rectangular shapes in the classroom?" Then, he drew a square on the blackboard, discussed its properties with the students and asked them to construct this shape using geometric stripes. Later, he invited a student to the blackboard and asked him to introduce this figure using the stripes. The same process was repeated for rectangle, rhombus, and parallelogram. By the time they arrived at the parallelogram, lesson time was over. While talking about the properties of quadrilaterals, he interacted with students and conducted class discussions. The following episode (EP5) exemplifies how Okan used responding actions in his second lesson and whether or not he focuses on ST. In this episode, he drew a rectangle on the blackboard, and then initiated a class discussion about how to draw a rectangle by using geometric stripes.

$1 \mathrm{O}: \mathrm{Ok}$, try to create a rectangle with your geometry strips considering their properties. [Initiation Prompt]

2 Ss: Teacher

3 O: Ok, who wants to come to the board? [Eliciting- Invite students to share their thoughts]. Ok, you can come and start telling it on the board [Eliciting-Invite students to share their thoughts] (asking the student's name "What is your name"?)

4 S: Ilknur (she says her name)

5 O: Well, Ilknur created the rectangle [as presented in following figure]. Yes, what do you want to say about the rectangle? What do you see when you look at it? [Eliciting- Invite students to share their thoughts]

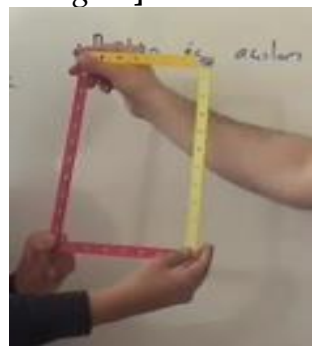

6 S: Rectangle

$7 \mathrm{O}$ : (smiling) Ok, you see a rectangle, very well [Evaluating-Confirming and EncouragingAppreciating the student] What else do you see? Ilknur, please tell your friends.

8 S. All angles are right.

9 O: Ok, what does your friend say? All angles are right [Repeating- Restating students' idea]. Next, yes Ilknur[Eliciting- Invite students to share their thoughts]

10 S: Parallel

$11 \mathrm{~S}$ : The sides are parallel to each other.

12 O: Opposite sides [Redirecting- Using a prompt to direct students' ideas/or solutions]

$13 \mathrm{~S}$ : Opposite sides are parallel to each other

14 O: Parallel to each other, and the lengths of opposite sides? [Redirecting- Asking a question to direct students' ideas/or solutions]

$15 \mathrm{~S}$ : Equal

16 O: Equal to each other [Extending- Extending students' thinking]. Yes, we see them now on this figure. Ok. 
As presented in the episode above, Okan frequently used eliciting questions to invite students to share their thoughts and to ask for a mathematical answer to reveal the knowledge of the students about the properties of the rectangle. He sometimes redirected ST by using prompts ("Opposite sides") or questions ("Parallel to each other, and the lengths of opposite sides?"). In addition, he also used other responding actions such as extending and repeating ST. In this episode, although Okan occasionally made small interventions and redirected the student, he structured the discussion by focusing on ST.

The objective of Okan's third lesson was to provide students to calculate the area of compound shapes consisting of triangle, rectangle, parallelogram, trapezoid and rhombus. When starting the lesson, Okan asked the following question to prepare the students for the lesson, "What do you think of when I say the circumference of a shape? What comes to your mind when I say the area of a shape?". Then, he continued with four different mathematical questions that required calculating circumference and area, and he formed mathematical discussions on each question. He also started a class discussion by examining the similarities and differences of the four quadrilaterals he drew on the blackboard. After talking about the circumferences and areas of the first three quadrilaterals, he proceeded to examine the differences between the 4 th quadrilateral and the previous ones. While talking about the similarities and differences of the quadrilaterals and the relationship between their circumference and area, he interacted with students and conducted class discussions. The following episode (EP5) exemplifies how Okan used responding actions and how his approach turned from focusing to non-focusing on ST.

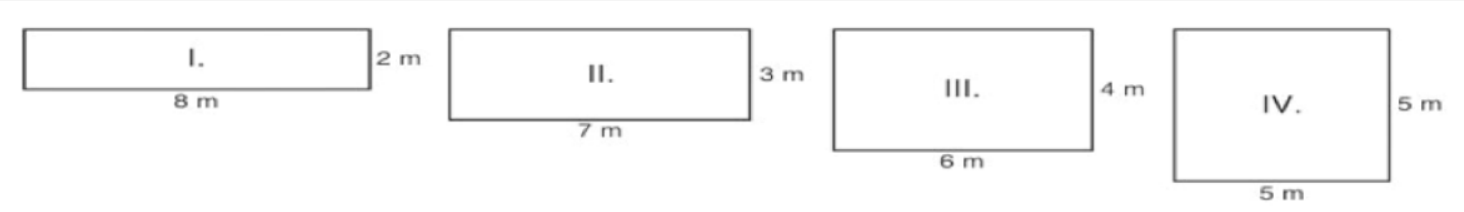

1 O: Well, is there any difference between the fourth shape and the first three shapes (Okan refers to the shapes above) [Initiation Question]

2 S: Yes

$3 \mathrm{O}$ : What kind of difference is there? [Eliciting- Invite students to explain their thoughts]

4 S: Square

5 O: What others? [Eliciting- Asking a question to get a mathematical answer]

6 Ss: Rectangle

7 O: Rectangle [Repeating- Restating student's idea] Very well. [Encouraging- Appreciating the students] Well, how do you interpret this change? When you look from the first shape to the fourth shape, how does it change? [Probing- Asking questions to invite comment] Yes. [Eliciting- Invite students to require explanation their thoughts]

8 S: The bottom length

9 O: How? [Probing-Asking questions to invite comment]

$10 \mathrm{~S}$ : The bottom length

$11 \mathrm{~S}$ : Base length

$12 \mathrm{~S}$ : Is the upper side long?

13 O: You can say it as the short side, the long side [Extending- Extending students' thinking]

$14 \mathrm{~S}$ : The long side is getting smaller, but the short side is getting bigger. I mean that it is going from rectangle to square.

15 O: Right. [Evaluating- Confirming]. So, what can we say more generally? As the difference between the sides gets smaller, (sides in the first figure, right?) how many centimeters is the difference between the two perpendiculars? [Eliciting-Asking a question to get mathematical answer]

16 S: 6

17 O: 6, isn't it? [Evaluating-Asking for approval]

18 Ss: 6

19 O: 6 [Repeating-Restating student's idea] Here? [Eliciting- Asking a question to get a mathematical answer] 
20 S: 2

21 O: Here? [Eliciting- Asking a question to get mathematical answer]

22 S: 0

$23 \mathrm{O}$ : So as the difference decreases, what is the distance between the perpendicular sides? What is getting bigger? [Eliciting- Asking a question to get a mathematical answer]

24 S: Short side

25 S: Area?

26 O: The areas are getting bigger, right? [Evaluating-Asking for approval]. When you look from the first shape to the fourth shape, the areas have increased, right? [Evaluating-Asking for approval]

27 Ss: Yes

28 O: Okay, then let's write a note [writing the following note on the board]. "As the difference between perpendicular sides decreases, the area increases." [Teaching- Making mathematical explanation]

In this episode, Okan aimed to create a discussion to provide the students to reach a generalization that the area of quadrilaterals increases as the difference in lengths between perpendicular sides decreases. In this classroom discussion, he initiated to enable students to reach this generalization and he mostly used eliciting ST, as in the whole of his third lesson. In the episode given above, he listened students step by step and sometimes extended their thinking by saying "So you can express it as the short side, the long side". By repeating ST, he provided the continuation of the discussion and at times showed that he appreciated them ("Very nice."). Sometimes, he evaluated ST by asking for approval ("6, isn't it?" or "The areas are getting bigger, right?") or confirming them ("Right"). He used questions that ask students to make comment and thus also tried to probe ST by using two consecutive questions ("Well, how do you interpret this change? When you look from the first shape to the fourth shape, how does it change?"). Although he started the discussion by focusing on ST by following their thoughts step by step, he distorted it with the following question that aimed to get a mathematical answer "So as the difference decreases, what is the distance between the perpendicular sides? What is getting bigger?". Then, he asked approval for his thought by saying "When you look from the first shape to the fourth shape, the areas have increased, right?". He repeated this result and asked the students to write it in their notebooks. Thus, in the last part of the episode [Lines 23-28], his approach turned from focusing to nonfocusing on ST. He put aside the ST, made a mathematical explanation ("As the difference between perpendicular sides decreases, the area increases") and ended the discussion as he had planned in his mind.

\subsection{Ferman's Responding to Student Thinking}

The data analysis showed that Ferman responded to ST by using different actions. Table 7 displays the ranking of Ferman's use of responding actions from the highest to the lowest percentage according to each lesson. As shown in Table 7, when responding to ST in his first two lessons, Ferman used nine different actions. In his first two lessons, Ferman used repeating action (24\%, $29 \%$ and $24 \%$, respectively) the most. Furthermore, Ferman's second most used action was eliciting (21\% $23 \%$ and $16 \%$, respectively). On the other hand, while Ferman's least used action was extending (3\%) in his first lesson, it was encouraging in his second and third lessons (2\% and $4 \%)$. Furthermore, when responding to ST in his third lesson, Ferman used eight different actions. In his third lesson, whereas Ferman used eliciting action the most, he used encouraging action at least. He did not use extending action in his third lesson. Moreover, different from his first two lessons, Ferman rarely used repeating action (8\%) in his third lesson. On the other hand, explaining (12\%) was an action that he used much more in his third lesson than in the first two lessons. In addition, although there were minor order changes in evaluating, teaching, and redirecting actions, they took place in the five most preferred actions in all three lessons. 
Table 7

Ranking of Ferman's responding actions from the highest to the lowest percentage

\begin{tabular}{clclclc}
\hline & \multicolumn{2}{c}{ Lesson\#1 } & \multicolumn{2}{c}{ Lesson\#2 } & \multicolumn{2}{c}{ Lesson\#3 } \\
\hline Order of actions & Actions & $\%$ & Actions & $\%$ & Actions & $\%$ \\
\hline 1 & Repeating & $24 \%$ & Repeating & $29 \%$ & Eliciting & $24 \%$ \\
3 & Eliciting & $21 \%$ & Eliciting & $23 \%$ & Redirecting & $16 \%$ \\
4 & Evaluating & $17 \%$ & Teaching & $17 \%$ & Evaluating & $14 \%$ \\
5 & Teaching & $14 \%$ & Extending & $10 \%$ & Teaching & $14 \%$ \\
6 & Redirecting & $7 \%$ & Evaluating & $9 \%$ & Explaining & $12 \%$ \\
7 & Encouraging & $6 \%$ & Probing & $4 \%$ & Probing & $8 \%$ \\
8 & Probing* & $5 \%$ & Redirecting & $4 \%$ & Repeating & $8 \%$ \\
9 & Explaining & $5 \%$ & Explaining & $3 \%$ & Encouraging & $4 \%$ \\
\hline
\end{tabular}

Note. ${ }^{*}$ Equal percentages are shown in bold; ${ }^{* *}$ The distribution of responding actions in the episodes of Ferman's each lesson was presented in Table 2 (see Appendix 2).

While explaining, extending, and encouraging were the least preferred actions in all lessons, probing action was steadily in rows six or seven. In other words, the order of probing action did not change much; however, the percentage of it increased to $8 \%$. Across three lessons, Ferman also used encouraging action with a low percentage varying from $2 \%$ to $6 \%$.

On the other hand, the data analysis revealed that like Okan, Ferman responded to ST by using various actions in his three lessons. However, while using these actions, he mostly did not focus on ST across three lessons. Table 8 shows Ferman's approach to focusing ST while responding to students during his lessons. As seen in Table 8, the number of episodes focused on ST was 2, 1 and 1, respectively and the number of episodes non-focused on ST was 6, 19 and 3, respectively, across three lessons. Although Ferman tried to focus on ST once or twice, he mostly followed a non-focus path to conduct the discussions in his lessons. He mostly continued the lesson by just revealing the ST and funneling them into the way in his mind. Furthermore, Ferman's focusing ST approach turned several times to the non-focusing ST approach while responding to students (see Table 8). That means, like Okan, he listened to students' responses and guided them at the beginning of the discussion, however, he then changed his approach to direct students to find an answer towards the end of the discussion.

Table 8

Ferman's approach to focus ST while responding to them during his lessons

\begin{tabular}{llll}
\hline & \multicolumn{3}{c}{ Number of episodes } \\
\cline { 2 - 4 } Ferman's approach to focus ST & Lesson\#1 & Lesson\#2 & Lesson\#3 \\
\hline Focusing(F-ST) & 2 & 1 & 1 \\
Non-Focusing (NF-ST) & 6 & 19 & 3 \\
Turning Focusing to Non-Focusing (F-ST & 2 & 3 & 1 \\
\& NF-ST) & & & - \\
Turning Non- Focusing to Focusing (NF- & - & - & 5 \\
ST\&F-ST) & & 23 & \\
\hline Total & 10 & & \\
\hline
\end{tabular}

The objective of Ferman's first lesson was to foster students' learning regarding the length of a circle and the arc length of a circle. He started his lesson to understand students' prior knowledge; therefore, he asked several questions such as "Do you remember the measure of the central angle and the length of an arc that subtends a central angle?" and "What was pi?". Then he wrote several mathematics questions on the board in turn. In this process, he usually invited the volunteer students on the board to solve the questions and he also made a class discussion on the solution of these questions. The following episode (EP2) exemplified how Ferman used responding actions in his first lesson while the student was working on the question on the board and how his approach 
turned from focusing to non-focusing on ST. In the question, a regular hexagon drawn in a circle with center $\mathrm{O}$ (see the figure below) is given and the difference between the measure of angle AOE and angle $\mathrm{AOB}$ is asked (What is the measure of the $\mathrm{s}(\widehat{\mathrm{OE}})-\mathrm{s}(\widehat{\mathrm{AOB}})$ ?). As shown in the following episode after writing the question on the board, he initiated a discussion by asking "What does this question ask?".

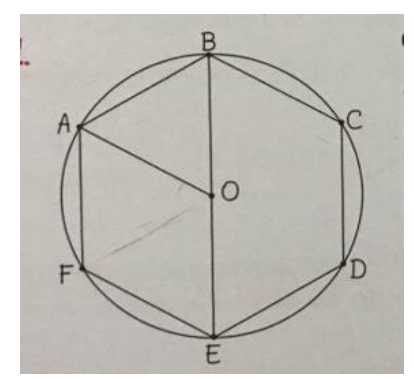

1 Ferman (F): Yes, what does this question ask? Who is willing to read and interpret the question? [Initiation Question]

$2 \mathrm{~S}$ : The angle AOE minus the angle AOB is equal.

3 F: AOE [Repeating- Restating students' idea].

4 S. Minus AOB is equal to each other.

5 F: AOB [Repeating- Restating students' idea].

$6 \mathrm{~S}: \mathrm{So}$, when we subtract it (the angle AOE) from it (the angle AOB), it becomes equal.

7 F: What do we say here? Let's say " $x$ ". Let's say " $y$ " here, okay? What was the angle AOE? " $x$ ". What was the angle AOB?. " $y$ " [Extending-Extending students' thinking]. Now, we are asked to subtract the angle " $y$ " from the angle " $x$ ". We are asked the difference between them, right? [Evaluating-Asking for approval]

8 S: Now, there

9 S: I have an idea.

$10 \mathrm{~F}$ : Yes, please [Eliciting- Asking a question to share students' thinking]

$11 \mathrm{~S}$ : Let me show [he is going to the board]. Now it was taken two sides here and it was taken one side here. Is this place twice there?

12 F: Is this place twice there? [Repeating- Restating students' idea].

$13 \mathrm{~S}$ : That is, here is " $y$ " and here is " $2 y$ ", right?

$14 \mathrm{~F}$ : It is a good question [Encouraging-Appreciating the students]. So, you mean, if we extend it like this, there is an inner part here and they are equal to each other. If here is " $y$ ", then here is $y$, this is $y$ [Explaining- Explaining students' thinking]

$15 \mathrm{~S}$ : It becomes $3 y$ in total. Then, $180^{\circ}$ divided by 3 .

16 F: So, what did we write instead of $x$ ? What did we find in the value of $x$ ? $2 y$. Is it correct? [Evaluating-Asking for approval]

17 S: Yes.

18 S: It becomes $3 y$ in total. Then, $180^{\circ}$ divided by 3

$19 \mathrm{~F}$ : When we subtract, $2 y-y$ is equal $y$, right? [Evaluating-Asking for approval]. Well, what is $\mathrm{y}$ ? [Eliciting- Asking a question to get mathematical answer]

20 S: $60^{\circ}$

$21 \mathrm{~F}$ : y is equal to $60^{\circ}$ [Repeating- Restating student's idea]. Thank you. [Encouraging- Appreciating the students]

As exemplified in this episode, Ferman used different actions to respond to ST. However, his tendency was frequently repeating the students' answers after he elicited ST by asking them to share their thinking. On the other hand, he often asked students' approval for the accuracy of their thoughts or the procedure ("We are asked the difference between them, right?", "Is it correct?" or "When we subtract, $2 y-y$ is equal $y$, right?"). By extending ("What was the angle AOE?. " $x$ ". What was the angle $A O B$ ?. " $y^{\prime \prime \prime \prime) ~ a n d ~ e x p l a i n i n g ~(" S o, ~ y o u ~ m e a n, ~ . . . ") ~ S T, ~ h e ~ m a d e ~ s t u d e n t s ' ~ c o n t r i b u t i o n ~ t o ~ t h e ~}$ discussion more meaningful to the whole class, and encouraged students to participate in the discussion, at times appreciating them ("Thank you."). Thus, Ferman mostly focused on ST [Lines 1-16] and constructed the discussion on the students' ideas. However, in the last part of the 
discussion [Lines 17-22], he turned his focusing ST approach to non-focusing ST. He answered the questions himself, asked the students for approval and concluded the discussion as he wanted.

The objective of Ferman's second lesson was to teach describing quadrilaterals such as rectangle, square, rhombus, parallelogram, and trapezoid, and describing the relationship between them. Therefore, in his second lesson, he aimed to introduce the properties of these quadrilaterals and to make a comparison of their properties so that the students could notice the relationship between them. At the beginning of the lesson, he started his teaching by asking the questions "What is quadrilateral, please define it?" and "Can you give me an example?". Next, he presented the properties and the definition of the rhombus, rectangle, square, trapezoid, and parallelogram, respectively. Additionally, during the lesson, Ferman preferred to use Geogebra with the interactive whiteboard to draw the quadrilaterals and talked about their properties and the relationships between them. While talking about the properties of each quadrilateral, he interacted with students and conducted class discussions. The following episode (EP23) shows the classroom discussion on the concept of the rectangle and exemplifies how Ferman used actions in his second lesson and how his approach turned from focusing to non-focusing on ST.

1 F: Ok. Please come to board. [Initiation expression]

2 S: [After the discussion about the rhombus is over, one of the students tells] Now, rectangle.

3 F: Rectangle. [Repeating- Restating student's idea]. Is a rectangle a rhombus? [Eliciting- Asking a question to get a mathematical answer]

4 S: (one of the students who are on the blackboard says) Yes

5 F: Is a rectangle a rhombus? [Repeating- Repeating the question]

6 Ss: (some of the students says) No

7 F: Why? [Probing- Asking a question to require clarification the students' thinking]

8 Ss: Yes, teacher.

9 S: (the students who are on the blackboard) No, no

$10 \mathrm{~F}$ : Is it a rhombus? [Repeating- Repeating the question]

11 Ss: No, teacher.

$12 \mathrm{~F}$ : What was one of the properties of a rhombus? [Eliciting- Asking a question to remember prerequisite (prior) knowledge]

$13 \mathrm{~S}$ : Opposite sides are parallel to each other

14 Ss: (more than one answer from the class, but none of them are understandable)

15 F: All sides are equal and parallel [Repeating-Restating students' idea]. Are all the sides of the rectangle equal? [Eliciting- Asking a question to get a mathematical answer]

16 Ss: No

17 F: Not all the sides are equal to each other. So, the rhombus doesn't come after that [Extending-

Extending students' thinking]. So, what comes next? [Eliciting- Asking a question to get a mathematical answer]

18 S: Square

19 F: Square [Evaluating-Confirming]. Ok. You can draw the same on the back of your paper.

As shown in the episode above, Ferman's approach of eliciting and repeating ST was prominent, as in the whole of his second lesson. He aimed to reveal ST by asking questions that require mathematical answers and remember the prior knowledge. Unlike his previous lesson, Ferman's use of repeating action included not only re-stating the students' thoughts but also repeating the question he asked. As Ferman repeated his question ("Is a rectangle a rhombus?") in succession, the students' answers differed as "Yes" or "No". This use of action prompted students to think more in detail. When a group of students answered the question by saying "No", Ferman asked them to explain the reason for their thought and this showed that he was trying to probe ST. Using these actions, he structured the discussion on ST so far [Lines 1-16]. However, in the final part of the discussion [Lines 17, 18 and 19], the spell was broken again, and he turned his focusing ST approach to a non-focusing ST approach. Ferman chose to extend ST instead of asking the student to extend his thinking ("Not all the sides are equal to each other. So, the rhombus doesn't come after that."). Then, he concluded the class discussion and even the lesson by confirming the answers of the students that the rhombus with equal sides was not a rectangle, it was a square. 
The objective of Ferman's third lesson was to teach translating a point, a line segment and different shapes. Therefore, at the beginning of the lesson, to inform about the objective of the lesson and to understand students' prior knowledge, Ferman initially told that "We will learn the translation?" and asked, "Do you know about the translation?". Next, after he gave the definition of the translation, he solved several questions regarding the translation of a point, a line segment and a quadrilateral throughout the lesson. Ferman preferred to use Geogebra with the interactive whiteboard to show the questions and make their solution. While teaching translation, he was in interaction with students and conducted class discussions. The following episode (EP3) displays the class discussion on how a point (Point D) can be translated. Furthermore, this episode exemplifies how Ferman used actions in the third first lesson while the student was working on the question on the board and how he could not focus on ST.

1 F: ( He writes a question on the interactive whiteboard). "Translate Point $D, 6$ units to the right, 3 units down". Who wants to do it? [Initiation Question]

2 F: (telling one of the male students) You can do it from your desk, or you can come to the board. [Eliciting- Asking a question to share students' thinking]

3 S: (the student comes to the board as shown in the following figure and tells) 6 units to the right

4 F: 6 units to the right [Repeating-Restating student's idea]. Mark it. (He intervenes to the student on the board, draws and writes himself). [Redirecting- Using a prompt to direct students' ideas/solution] Here, 6 units to the right. 3 units down. Point it again. As I showed it, point it with the arrow. Write, 3 units down. (He says to the student and makes the student write on the blackboard). [Redirecting- Using a prompt to directing students' ideas/solution]. Is it correct? [Evaluating-Asking for approval]

5 Ss: Yes

6 F: We translated point $D, 6$ units to the right, 3 units down... I count 6 units to the right, and 3 units down. The definition says that the displacement is in a certain direction. [Teaching-Making mathematical explanation or operations]. Now, if I change its order, 3 units down, 6 units to the right? [Eliciting- Asking a question to share students' thinking]

7 Ss: We find the same point.

8 F: Please, write this note in your notebooks as well.

In this episode, Ferman asked students to translate Point D, 6 units to the right, 3 units down. As it is seen in the episode above, he mostly used eliciting action to respond to ST as in his first two lessons. He invited a student to the board to share his solution with the class. What differs from his previous lessons was that he redirected students more in the third lesson. He guided the student on the board by giving some directives like "Mark it" or "Here, 6 units to the right. 3 units down. Point it again." In fact, this non-focusing approach showed that he wanted not to allow the student to explain his solution or to solve it on his own by thinking about the place where he was stuck, but to reach the correct answer by leading and to continue the lesson quickly. Unlike his previous lessons, he restated the students' ideas relatively less. He sometimes asked the whole class for the correctness of the student's solution on the board ("Is it correct?"). Finally, he made some mathematical explanations and ended the discussion.

\section{Discussion and Conclusion}

Responding is considered a difficult noticing skill to develop for both pre-service and in-service teachers since it is a visible action linked to internal processes of attending and interpreting students' mathematical thinking (Barnhart \& van Es, 2015; Land et al., 2019; Sánchez-Matamoros et al., 2019). The findings of this study displayed PSMTs' ways of responding to ST in their teaching experiences and the extent they focused on ST while responding to them.

Our findings initially revealed that the PSMTs could use different types of actions such as eliciting, repeating, redirecting, teaching and encouraging to respond to ST during their lessons. As the researchers (e.g., Herbel-Eisenmann \& Breyfolge, 2005; Monson et al., 2020) pointed out in the traditional classrooms, teachers usually apply IRE pattern and within the IRE pattern teachers typically ask a question, students offer responses and then teachers give evaluative feedback or confirm students' responses. That is, teachers' responses are limited to a few responding actions 
such as confirmation, evaluation, correcting or leading ST toward the correct answer (Monson et al., 2020). In this study, PSMTs' use of various actions in their lessons was a remarkable finding because as Lim et al. (2020) pointed out, PSMTs' use of various responding actions signals that they could go beyond only confirming or evaluating students' responses. However, the findings displayed that PSMTs' preferences of responding actions differed across three lessons. That is, although PSMTs dominantly used several actions such as eliciting, evaluating and repeating in each of their lessons, their responding actions did not follow a single path or a pattern for three lessons. For example, while one of the PSMTs (Ferman) preferred to use repeating the most in his first two lessons, he mostly used eliciting in his last lesson. One of the possible reasons for this finding may be participating PSMTs' lack of both theoretical knowledge about characteristics of a good response and teaching experience under natural classroom setting. As emphasized by NCTM (2014), there is no single best way to respond to ST; however, the teacher's response should focus on ST and deepen students' conceptual understanding while moving their thinking forward. So, PSMTs initially need theoretical knowledge about characteristics of good responses and the responding actions which are productive to focus on ST, and then they need to find opportunities to apply their knowledge in real classroom settings. Therefore, providing both theoretical and practice-based opportunities for PSMTs to respond to ST appropriately should be one of the goals of the teacher education programs. In addition, PSMTs' preferred teaching methods, such as traditional, activity-based or technology-supported (e.g., Geogebra) might have influenced their responding actions. Since the aim of this study was not directly to examine PSMTs' responding pattern during their lessons, to diagnose how consciously PSMTs use responding actions in their lessons, future research could investigate whether or not there is a pattern among their responding actions according to the lessons.

Among the responding actions, one of the most preferred actions was eliciting for both of PSMTs. Eliciting can be an important first step in an ongoing process of building on and supporting students' mathematical thinking (Ellis et al., 2019). Teachers must understand students' existing thinking before they can hope to build on it and so they need to elicit what students have already thought about and done (Jacobs \& Empson, 2016). Therefore, PSMT's use of eliciting action frequently in their lessons was a valuable finding. PSMTs' theoretical knowledge and practical experience regarding how to question and elicit ST, which they obtained in some of mathematics education courses before participating to this study, may likely have helped their dominant use of eliciting action. However, the findings also revealed that while both PSMTs asked questions or used several prompts to elicit ST, they struggled with how to follow up ST after they elicited. Similar to our finding, Shaughnessy and Boerst's (2018) study indicated that the pre-service teachers elicited all of the steps of the student's process for solving the problem; however, their questions were often not clear or targeted. Accordingly, they suggested that although pre-service teachers were promising in terms of eliciting, they needed to improve in being able to ask eliciting and follow-up questions in better ways.

On the other hand, in addition to eliciting action, PSMTs applied frequently repeating action to respond to ST. The teacher can use revoicing, which we call repeating, to align students to a particular argument or way of thinking about mathematics (Franke et al., 2007). In this study, the possible explanation of PSMTs' frequent use of repeating action may be related to their efforts to ensure the continuity of the discussion. Moreover, like many teachers, who follow the IRE pattern (Monson et al., 2020), our participating PSMTs also used evaluating action while responding to ST.

Explaining, extending and probing ST were less preferred actions than the other actions for both PSMTs. Probing ST allows the student the opportunity to articulate a correct and complete explanation when the initial student explanation was ambiguous, incomplete, or incorrect (Franke et al., 2009). Therefore, the PSMTs' low use of these three actions might have prevented them from structuring their lessons on ST. In line with this, the findings also displayed that in most of the episodes, PSMTs' general responding approaches were not to focus on ST in their lessons. Furthermore, although both PSMTs tended not to focus on ST in their lessons, there were 
individual differences between their responding approaches. Unlike Ferman, Okan made more effort in terms of focusing on ST. The findings also showed that there were several episodes where PSMTs changed their approach from focusing to non-focusing ST or non-focusing to focusing ST. The change in Ferman's approach was only in the direction of focusing to non-focusing ST. While at the beginning of the discussion, Ferman listened to students' responses and guided them, he then changed his approach to direct students to find an answer towards the end of the discussion. On the other hand, there were episodes in Okan's classes where he started non-focusing ST and turned to focusing ST. In these episodes, he first tried to elicit the ST and continued the discussion in the direction he planned, then focused on the ST and guided them to reach some inferences themselves. One reason for the differences in the two PSMTs' responding approaches may be their different GPAs considered in terms of content knowledge and pedagogical content knowledge. Okan's higher GPA may be a reason for his efforts towards focusing on ST. Also, another reason for the differences may be that the topics PSMTs taught in the 3rd lesson were not the same. If they had taught the same topics, it would have been possible to make a more accurate comparison of their responding approaches. Since PSMTs were not interviewed about the reasons for their actions in response to ST and their responding approaches, future studies may examine their reflections through interviews to better understand the rationale for their actions in response to ST and may compare their responding approaches more comprehensively.

As Munson (2019) indicated, not all responses are equally productive for promoting student learning, this study showed that responding to ST does not always mean focusing and deepening them. A good response should be based on ST and involve interaction with the student to leave space for the student's future thinking (Monson et al., 2020).

\section{Limitation and Future Implications}

This study was only a descriptive study limited to three lessons of two PSMTs. Therefore, the findings provided information about PSMTs' ways of responding to ST for only three lessons. As Dong et al. (2019) expressed, because it is likely difficult to draw accurate and robust conclusions by investigating teacher's practice in a few lessons, future studies may be conducted in more lessons of more PSMTs. Furthermore, to better understand the actions they used in response to ST, PSMTs should be followed for a longer period during a unit of consecutive lessons, and they also should be interviewed about their responding actions. The findings of this study may help mathematics teacher educators to understand the PSMTs' ways of responding to the ST and their tendencies towards being able to focus on ST while responding to students. Responding to ST is a difficult practice to enact effectively for novices (Hallman-Thrasher, 2017). However, as Jacobs et al. (2010) expressed pre-service teachers' responding skills can be improved through experience and time by professional development support. Therefore, this study suggests that mathematics teacher educators should provide opportunities for PSMTs to learn about how they can respond to ST during their teacher education program, both at a theoretical and practical level. Specifically, as Monson et al. (2020) used in their study, mathematics teacher educators might offer practical experience for pre-service teachers to work on student work by interviewing them through the Interview Module which provides a structure to PSMTs for good response. This study also suggests that more research is needed for investigating PSMTs' ways of responding. Future studies may focus on the development of PSMTs' responding skills and even the development of other noticing skills. Providing opportunities for PSMTs to watch and analyze their own videos after their teaching experience and giving feedback on their responding actions could be supportive for their development. Thus, it may be possible to prepare future teachers to build on ST by developing their responding skills. 


\section{References}

Abdulhamid, L., \& Venkat, H. (2018). Primary mathematics teachers' responses to students' offers: An 'elaboration' framework. The Journal of Mathematical Behavior, 51, 80-94. https://doi.org/10.1016/j.jmathb.2017.08.007

Barnhart, T., \& van Es, E. (2015). Studying teacher noticing: Examining the relationship among pre-service science teachers' ability to attend, analyze and respond to student thinking. Teaching and Teacher Education, 45, 83-93. https://doi.org/10.1016/j.tate.2014.09.005

Brodie, K. (2008). Describing teacher change: Interactions between teacher moves and learner contributions. In Proceedings of the fifth international mathematics education and society conference (MES5) (pp. 31-50). Universidade de Lisboa-Department of Education.

Bywater, J. P., Chiu, J. L., Hong, J., \& Sankaranarayanan, V. (2019). The Teacher Responding Tool: Scaffolding the teacher practice of responding to student ideas in mathematics classrooms. Computers $\mathcal{E}$ Education, 139, 16-30. https://doi.org/10.1016/j.compedu.2019.05.004

Chamberlin, M. T. (2005). Teachers' discussions of students' thinking: Meeting the challenge of attending to students' thinking. Journal of Mathematics Teacher Education, 8(2), 141-170. https://doi.org/10.1007/s10857-005-4770-4

Conner, A., Singletary, L. M., Smith, R. C., Wagner, P. A., \& Francisco, R. T. (2014). Teacher support for collective argumentation: A framework for examining how teachers support students' engagement in mathematical activities. Educational Studies in Mathematics, 86(3), 401-429. https:// doi.org/10.1007/s10649-014-9532-8

Dong, L., Clarke, D., Cao, Y., Wang, L., \& Seah, W. T. (2019). Teacher questioning practices over a sequence of consecutive lessons: A case study of two mathematics teachers. Sustainability, 11(1), 139. https://doi.org/10.3390/su11010139

Ellis, A., Özgür, Z., \& Reiten, L. (2019). Teacher moves for supporting student reasoning. Mathematics Education Research Journal, 31(2), 107-132. https://doi.org/10.1007/s13394-018-0246-6

Fennema, E., Carpenter, T. P., Franke, M. L., Levi, L., Jacobs, V. R., \& Empson, S. B. (1996). A longitudinal study of learning to use children's thinking in mathematics instruction. Journal for research in mathematics education, 27(4), 403-434. https://doi.org/10.2307/749875

Franke, M. L., \& Kazemi, E. (2001). Teaching as learning within a community of practice: Characterizing generative growth. In T. Wood, B. C. Nelson, \& J. Warfield (Eds.), Beyond classical pedagogy in elementary mathematics: The nature of facilitative teaching (pp. 47-74). Erlbaum.

Franke, M. L., Carpenter, T. P., Levi, L., \& Fennema, E. (2001). Capturing teachers' generative change: A follow-up study of professional development in mathematics. American educational research journal, 38(3), 653-689. https:/ / doi.org/10.3102/00028312038003653

Franke, M. L., Webb, N. M., Chan, A., \& Battey, D. (2007). Eliciting student thinking in elementary school mathematics classrooms. CRESST Report 725. National Center for Research on Evaluation, Standards, and Student Testing (CRESST).

Franke, M. L., Webb, N. M., Chan, A. G., Ing, M., Freund, D., \& Battey, D. (2009). Teacher questioning to elicit students' mathematical thinking in elementary school classrooms. Journal of Teacher Education, 60(4), 380-392. https://doi.org/10.1177/0022487109339906

Gaspard, C., \& Gainsburg, J. (2020). Abandoning questions with unpredictable answers. Journal of Mathematics Teacher Education, 23(6), 555-577. https:// doi.org/10.1007/s10857-019-09440-5

Hallman-Thrasher, A. (2017). Prospective elementary teachers' responses to unanticipated incorrect solutions to problem-solving tasks. Journal of Mathematics Teacher Education, 20(6), 519-555. https://doi.org/10.1007/s10857-015-9330-y

Herbel-Eisenmann, B. A., \& Breyfogle, M. L. (2005). Questioning our patterns of questioning. Mathematics Teaching in the Middle School, 10(9), 484-489. https:// doi.org/10.5951/MTMS.10.9.0484

Jacobs, V. R., \& Ambrose, R. C. (2008). Making the most of story problems. Teaching Children Mathematics, 15(5), 260-266. https://doi.org/10.5951/TCM.15.5.0260

Jacobs, V. R., Lamb, L. C., \& Philipp, R. A. (2010). Professional noticing of children's mathematical thinking. Journal for Research in Mathematics Education, 41(2), 169-202. https:// doi.org/10.5951/jresematheduc.41.2.0169

Jacobs, V. R., Lamb, L. L., Philipp, R. A., \& Schappelle, B. P. (2011). Deciding how to respond on the basis of children's understanding. In M. Sherin, V. Jacobs, \& R. Philipp (Eds.), Mathematics teacher noticing: Seeing through teachers' eyes (pp. 97-116). Routledge. 
Jacobs, V. R., \& Empson, S. B. (2016). Responding to children's mathematical thinking in the moment: An emerging framework of teaching moves. ZDM, 48(1-2), 185-197. https://doi.org/10.1007/s11858-0150717-0

Krupa, E. E., Huey, M., Lesseig, K., Casey, S., \& Monson, D. (2017). Investigating secondary prospective teachers' noticing of student thinking. In E. O. Schack, J. Wilhelm, \& M. H. Fisher (Eds.), Teacher noticing: Bridging and broadening perspectives, contexts, and frameworks research in mathematics education (pp. 49-72). Springer.

Land, T. J., Tyminski, A. M., \& Drake, C. (2019). Examining aspects of teachers' posing of problems in response to children's mathematical thinking. Journal of Mathematics Teacher Education, 22(4), 331-353. https://doi.org/10.1007/s10857-018-9418-2

Lee, M. Y., \& Francis, D. C. (2018). Investigating the relationships among elementary teachers' perceptions of the use of students' thinking, their professional noticing skills, and their teaching practices. The Journal of Mathematical Behavior, 51, 118-128. https://doi.org/10.1016/j.jmathb.2017.11.007

Lim, W., Lee, J. E., Tyson, K., Kim, H. J., \& Kim, J. (2020). An integral part of facilitating mathematical discussions: Follow-up questioning. International Journal of Science and Mathematics Education, 18(2), 377398. https://doi.org/10.1007/s10763-019-09966-3

Males, L. M. (2017). Using video of peer teaching to examine grades 6-12 preservice teachers' noticing. In E. O. Schack, J. Wilhelm, \& M. H. Fisher (Eds.), Teacher noticing: Bridging and broadening perspectives, contexts, and frameworks research in mathematics education (pp. 91-109). Springer.

Mason, J. (2002). Researching your own practice: The discipline of noticing. Routledge Falmer.

Mehan, H. (1979). Learning lessons: Social organization in the classroom. Harvard University Press.

Monson, D., Krupa, E., Lesseig, K., \& Casey, S. (2020). Developing secondary prospective teachers' ability to respond to student work. Journal of Mathematics Teacher Education, 23(2), 209-232. https://doi.org/10.1007/s10857-018-9420-8

Munson, J. (2019). After eliciting: Variation in elementary mathematics teachers' discursive pathways during collaborative problem solving. The Journal of Mathematical Behavior, 56, 100736. https:// doi.org/10.1016/j.jmathb.2019.100736

National Council of Teachers of Mathematics [NCTM]. (2000). Principles and standards for school mathematics. Author.

National Council of Teachers of Mathematics [NCTM]. (2014). Principles to actions: Ensuring mathematical success for all. NCTM.

National Council of Teachers of Mathematics [NCTM]. (2018). Catalyzing change in high school mathematics: Initiating critical conversations. Author

Philipp, R., Fredenberg, M., \& Hawthorne, C. (2017). Examining student thinking through teacher noticing: Commentary. In E. O. Schack, J. Wilhelm, \& M. H. Fisher (Eds.), Teacher noticing: Bridging and broadening perspectives, contexts, and frameworks research in mathematics education (pp. 113-120). Springer.

Sánchez-Matamoros, G., Fernández, C., \& Llinares, S. (2019). Relationships among prospective secondary mathematics teachers' skills of attending, interpreting and responding to students' understanding. Educational Studies in Mathematics, 100(1), 83-99. https://doi.org/10.1007/s10649-0189855-y

Santagata, R., Zannoni, C., \& Stigler, J. W. (2007). The role of lesson analysis in pre-service teacher education: An empirical investigation of teacher learning from a virtual video-based field experience. Journal of mathematics teacher education, 10(2), 123-140. https:// doi.org/10.1007/s10857-007-9029-9

Shaughnessy, M., \& Boerst, T. A. (2018). Uncovering the skills that preservice teachers bring to teacher education: The practice of eliciting a student's thinking. Journal of Teacher Education, 69(1), 40-55. https://doi.org/10.1177/0022487117702574

Sherin, M. G. (2002). A balancing act: Developing a discourse community in a mathematics classroom. Journal of Mathematics Teacher Education, 5, 205-233. https://doi.org/10.1023/A:1020134209073

Sherin, M. G., \& Han, S. Y. (2004). Teacher learning in the context of a video club. Teaching and Teacher Education, 20(2), 163-183. https:// doi.org/10.1016/j.tate.2003.08.001

Sherin, M. G., \& van Es, E. A. (2005). Using video to support teachers' ability to notice classroom interactions. Journal of Technology and Teacher Education, 13(3), 475-491.

Sherin, M. G., \& van Es, E. A. (2009). Effects of video club participation on teachers' professional vision. Journal of Teacher Education, 60(1), 20-37. https:// doi.org/10.1177/0022487108328155 
Sherin, M. G., Russ, R. S., \& Colestock, A. A. (2011). Accessing mathematics teachers' in-the-moment noting. In M. G. Sherin, V. R. Jacobs, \& R. A. Philipp (Eds.), Mathematics teacher noticing: Seeing through teachers' eyes (pp. 79-94). Routledge.

Son, J. W. (2016). Preservice teachers' response and feedback type to correct and incorrect student-invented strategies for subtracting whole numbers. The Journal of Mathematical Behavior, 42, 49-68. https://doi.org/10.1016/j.jmathb.2016.02.003

Star, J. R., \& Strickland, S. K. (2008). Learning to observe: Using video to improve preservice mathematics teachers' ability to notice. Journal of Mathematics Teacher Education, 11, 107-125. https://doi.org/10.1007/s10857-007-9063-7

Star, J. R., Lynch, K., \& Perova, N. (2011). Using video to improve preservice mathematics teachers' abilities to attend to classroom features. In M. G. Sherin, V. R. Jacobs, \& R. A. Philipp (Eds.), Mathematics teacher noticing: Seeing through teachers' eyes (pp. 117-133). Routledge.

Strauss, A. \& Corbin, J. (1990). Basics of qualitative research: Grounded theory procedures and techniques. Sage.

Tyminski, A. M., Simpson, A. J., Land, T. J., Drake, C., \& Dede, E. (2020). Prospective elementary mathematics teachers' noticing of childrens' mathematics: A focus on extending moves. Journal of Mathematics Teacher Education, 1-29. https:// doi.org/10.1007/s10857-020-09472-2

van Es, E. A., \& Sherin, M. G. (2002). Learning to notice: Scaffolding new teachers' interpretations of classroom interactions. Journal of Technology and Teacher Education, 10(4), 571-596.

van Es, E. A., \& Sherin, M. G. (2008). Mathematics teachers' "learning to notice" in the context of a video club. Teaching and Teacher Education, 24(2), 244-276. https:/ / doi.org/10.1016/j.tate.2006.11.005

Wood, T. (1998). Alternative patterns of communication in mathematics classes: Funneling or focusing? In H. Steinbring, M. Bartolini Bussi, \& A. Sierpinska (Eds.), Language and communication in the mathematics classroom (pp. 167-178). National Council of Teachers of Mathematics.

Yin, R. K. (2003). Case study research: Design and methods (3rd ed.). Sage. 

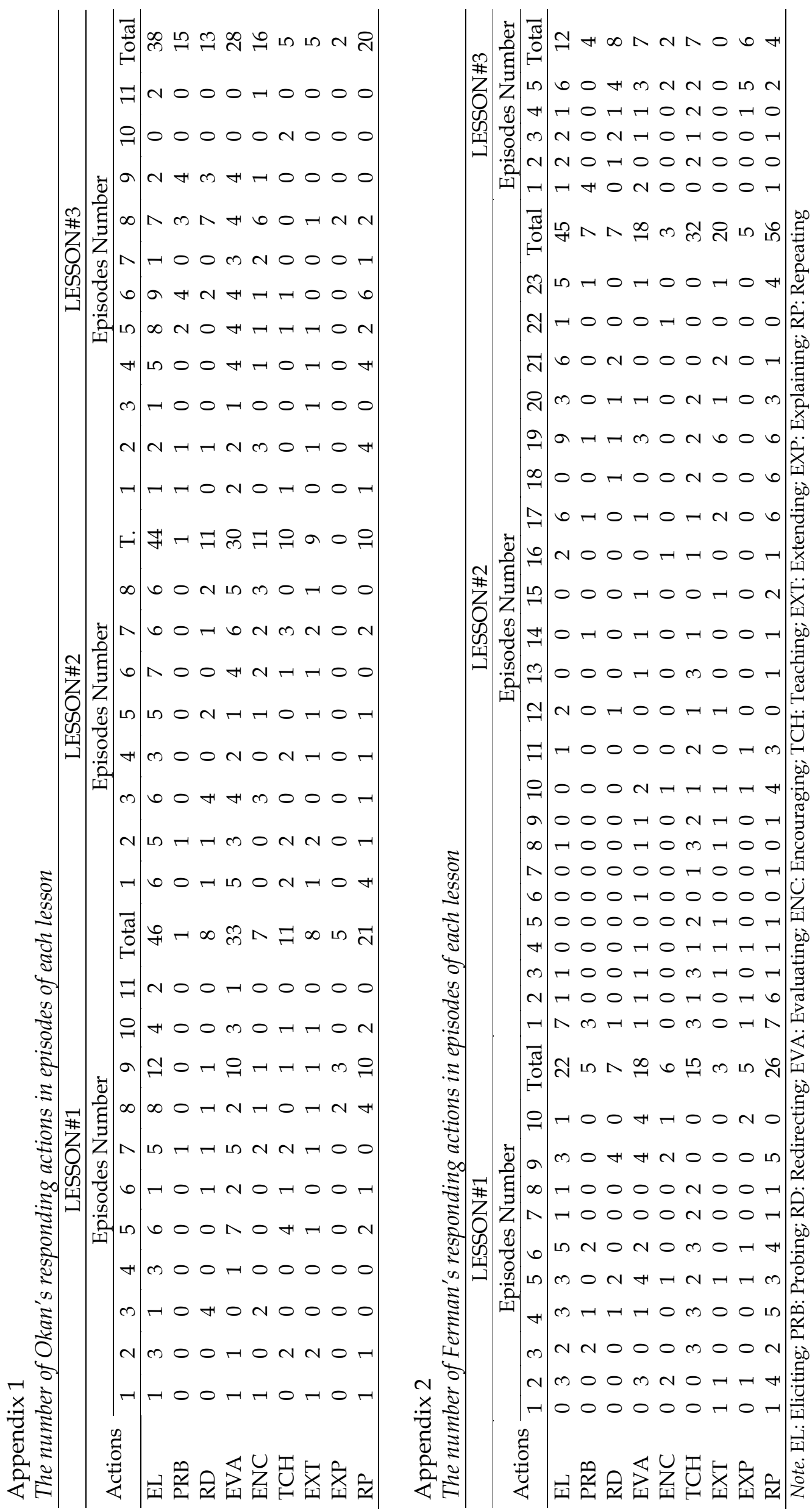